\title{
Prevalence and pattern of lipid profile among patients with diabetes mellitus attending a tertiary teaching hospital in Nepal
}

\author{
Kafle R $\mathbf{R}^{1}$, Kadel AR ${ }^{2}$ iD
}

${ }^{1}$ Rita Kafle, Lecturer, Department of Emergency and General Practice; ${ }^{2}$ Anuj Raj Kadel, Department of Medical Education; Kathmandu Medical College Teaching Hospital, Kathmandu, Nepal.

\begin{abstract}
Background: Dyslipidemia, a well-known major risk factor for coronary heart disease, is commonly associated with macro-vascular complications in patients with diabetes mellitus. Increased level of triglycerides and reduced levels of HDL cholesterol are common lipid abnormalities in diabetes.

Objectives: The aim of the study was to study the prevalence and pattern of lipid abnormalities among diabetic patients attending general practice outpatient department in Kathmandu Medical College Teaching Hospital.

Methodology: This is a descriptive cross-sectional study conducted in the Department of General Practice and Emergency of Kathmandu Medical College Teaching Hospital, Duwakot, Bhaktapur. Convenience sampling technique was used.After obtaining informed consent, 120 diabetic patients from January 2020 to March 2020 were included. The data collected was entered in the Statistical Package for the Social Sciences software and analyzed. Ethical clearance was taken from the Institutional Review Committee of Kathmandu Medical College.

Results: The average TC, HDL, TG and LDL level among the female participants were $186.18 \mathrm{mg} / \mathrm{dl}, 41.91 \mathrm{mg} / \mathrm{dl}, 194.63$ $\mathrm{mg} / \mathrm{dl}, 111.88 \mathrm{mg} / \mathrm{dl}$ respectively and $186.30 \mathrm{mg} / \mathrm{dl}, 38.80 \mathrm{mg} / \mathrm{dl}, 205.60 \mathrm{mg} / \mathrm{dl}, 125.80 \mathrm{mg} / \mathrm{dl}$ among the male participants respectively. Eighty-five (71\%) patients had a low HDL level. Total cholesterol was found to be high in 38(32\%) participants. LDL cholesterol was high in 77(64\%) participants. The triglyceride level was high in $85(71 \%)$ participants.

Conclusion: This study showed that some diabetic individuals have a lipid abnormality while others did not. This shines light on the importance of regular testing for lipid profile in diabetic individuals because we cannot reasonably predict when a patient will develop dyslipidemia.
\end{abstract}

Key words: Diabetes mellitus; Dyslipidemia; Prevalence.

\section{Access this article online}

Website: www.jkmc.com.np

DOI: https://doi.org/10.3126/jkmc.v9i3.36414

\section{HOW TO CITE}

Kafle R, Kadel AR. Prevalence and pattern of lipid profile among patients with diabetes mellitus attending a tertiary teaching hospital in Nepal. J Kathmandu Med Coll. 2020;9(3):150-3.

Address for correspondence

Dr. Rita Kafle

Lecturer, Department of General Practice and Emergency Medicine

Kathmandu Medical College Teaching Hospital,

Sinamangal, Kathmandu, Nepal.

E-mail: dr.rkafle@gmail.com

Copyright @ 2020 Journal of Kathmandu Medical College (JKMC) ISSN: 2019-1785 (Print), 2091-1793 (Online)

(i) (S) This work is licensed under a Creative Commons Attribution-Non Commercial 4.0 International License.

\section{INTRODUCTION}

Drevalence of diabetes mellitus (DM) is growing - rapidly worldwide. Global prevalence of DM among adults is estimated to be $6.4 \%$, affecting 285 million people in 2010 and is expected to increase to $7.7 \%$ affecting 439 million people by $2030^{\prime}$. The prevalence of DM in Nepal is $8.5 \%^{2}$.

Diabetes mellitus is a common secondary cause of dyslipidemia. The prevalence of dyslipidemia in Diabetes mellitus is $95 \%{ }^{3}$. In diabetes mellitus the lipid abnormalities are more prevalent because major key enzymes and lipid metabolism pathways are affected due to deficiency of insulin production and secretion ${ }^{4}$. The dyslipidemia is major risk factor for coronary heart disease $(\mathrm{CHD})^{5}$. Hence, DM is a risk factor for atherosclerosis which can potentially cause dreaded ailments like coronary heart disease and cerebrovascular disease. Micro-vascular complications are related to 
poor glycemic control and duration of diabetes, but risk of macro-vascular complications remains to be dyslipidemia, smoking and hypertension ${ }^{6}$. Dyslipidemia in DM usually manifests as an increase in Low Density Lipoprotein (LDL) and triglyceride (TG) concentrations?. Studies have shown that dyslipidemia is a significant independent predictor of coronary heart disease in patient with type $2 \mathrm{DM}^{8}$. The cardiovascular disease is the cause of morbidity and mortality in patient with DM because of disturbance in the levels of lipoproteins i.e. serum triglyceride $69 \%$, serum cholesterol $56.6 \%$ and LDL $77 \%$ 9,10.

In DM, associated hyperglycemia, obesity and insulin changes highly accelerate the progression to atherosclerosis ${ }^{11,12}$. In this study, we aim to see the association between lipid profile abnormality and a diabetic individual, keeping in mind that early detection and treatment of lipid abnormalities can minimise the risk of atherogenic cardiovascular disorder in type 2 diabetes mellitus.

The objective of this study was to obtain the fasting blood glucose level and lipid profile of the participants and map out the pattern of lipid profile including total cholesterol (TC), HDL cholesterol, LDL cholesterol and triglyceride among diabetic patients attending general practice outpatient department in Kathmandu Medical College (KMC) Teaching Hospital, Duwakot, Nepal.

\section{METHODOLOGY}

This descriptive cross-sectional study was conducted from January 2020 to March 2020, in the General Practice outpatient department of Kathmandu Medical College Teaching Hospital, Duwakot, Bhaktapur.

Sample size of 120 was calculated as $N=Z^{2} p(1-p) / d^{2}$. $p$ was taken as $8.4 \%$ from the study "Prevalence of type 2 diabetes in Nepal: a systematic review and meta-analysis from 2000 to $2014^{\prime \prime 13}$, hence sample size calculated was 120.

Adult patients of age 30 years and above were included in the study by purposeful sampling technique and informed consent was obtained. Patients having hypertension, patients on lipid lowering drugs, history of liver, kidney or cardiac failure were excluded.

Detailed history, examination, and anthropometric measurement were recorded in study proforma. Fasting blood sugar and lipid profile was done after a minimum of eight hours of overnight fasting. The National Cholesterol Education Program-Adult Treatment Panel III 2018(NCEPATP III) criteria was followed for diagnosis of lipid abnormality if total cholesterol $>200 \mathrm{mg} / \mathrm{dl}$, triglyceride $>150 \mathrm{mg} / \mathrm{dl}, \mathrm{LDL}>100 \mathrm{mg} / \mathrm{dl}, \mathrm{HDL}<40 \mathrm{mg} / \mathrm{dl}$ in males and $\leq 50 \mathrm{mg} / \mathrm{dl}$ in females ${ }^{14}$.

The data was collected using a semi-structured questionnaire which was entered into and analyzed in Statistical Package for the Social Sciences (SPSS) Statistics for Windows, version 16.0 (SPSS Inc., Chicago, III., USA). Descriptive statistics have been presented as frequency, percentage, mean, and standard deviation.

\section{RESULTS}

A total of 120 diabetic patients were included, out of which 55 (45.8\%) were male and 65(54.2\%) were female. Mean age of the patients was $51.8 \pm 12.1$ years. The mean fasting blood sugar (FBS) was $136 \pm 48.2 \mathrm{mg} / \mathrm{dl}$ and mean body mass index (BMI) was $25.9 \pm 3.5 \mathrm{~kg} / \mathrm{m}^{2}$.

The mean values of the lipid profiles in this study (Table 1) were TC: $186.2 \pm 49.1 \mathrm{mg} / \mathrm{dl}$, high density lipoprotein (HDL) cholesterol: $40.5 \pm 7.3 \mathrm{mg} / \mathrm{dl}$, triglycerides (TG): $199.7 \pm 89.6 \mathrm{mg} / \mathrm{dl}$, low density lipoprotein (LDL) cholesterol: $118.2 \pm 40.9 \mathrm{mg} / \mathrm{dl}$.

Regarding gender wise distribution of Lipid profile (Table 2), the average values of TC, HDL, TG and LDL were found to be different when compared between males and females.

Figure1 showed 85 (71\%) participants had a low HDL level, 38 (32\%) participants had high TC., 77 (64\%) of participants had high LDL cholesterol and 85 (71\%) participants had high TG.

Table 1: Mean values of lipid profiles in diabetes mellitus

\begin{tabular}{lc}
\hline Lipid Parameters & Mean $\pm \mathbf{S D}(\mathbf{m g} / \mathbf{d l})$ \\
\hline Total Cholesterol (TC) & $186.2 \pm 49.1$ \\
\hline High Density Lipoprotein (HDL) Cholesterol & $40.5 \pm 7.3$ \\
\hline Triglycerides (TG) & $199.7 \pm 89.6$ \\
\hline Low Density Lipoprotein (LDL) Cholesterol & $118.2 \pm 40.9$ \\
\hline
\end{tabular}


Table 2: Gender wise distribution of lipid profiles

\begin{tabular}{lcccc}
\hline Sex & TC $(\mathbf{m g} / \mathbf{d l})($ Mean \pm SD) & HDL $(\mathbf{m g} / \mathbf{d l})($ Mean \pm SD) & TG $(\mathbf{m g} / \mathbf{d l})($ Mean \pm SD) & LDL $(\mathbf{m g} / \mathbf{d l})($ Mean \pm SD) \\
Female & $186.18 \pm 50.67$ & $41.91 \pm 7.69$ & $194.63 \pm 97.04$ & $111.88 \pm 44.41$ \\
Male & $186.30 \pm 46.78$ & $38.80 \pm 6.30$ & $205.60 \pm 78.55$ & $125.80 \pm 34.41$ \\
\hline
\end{tabular}

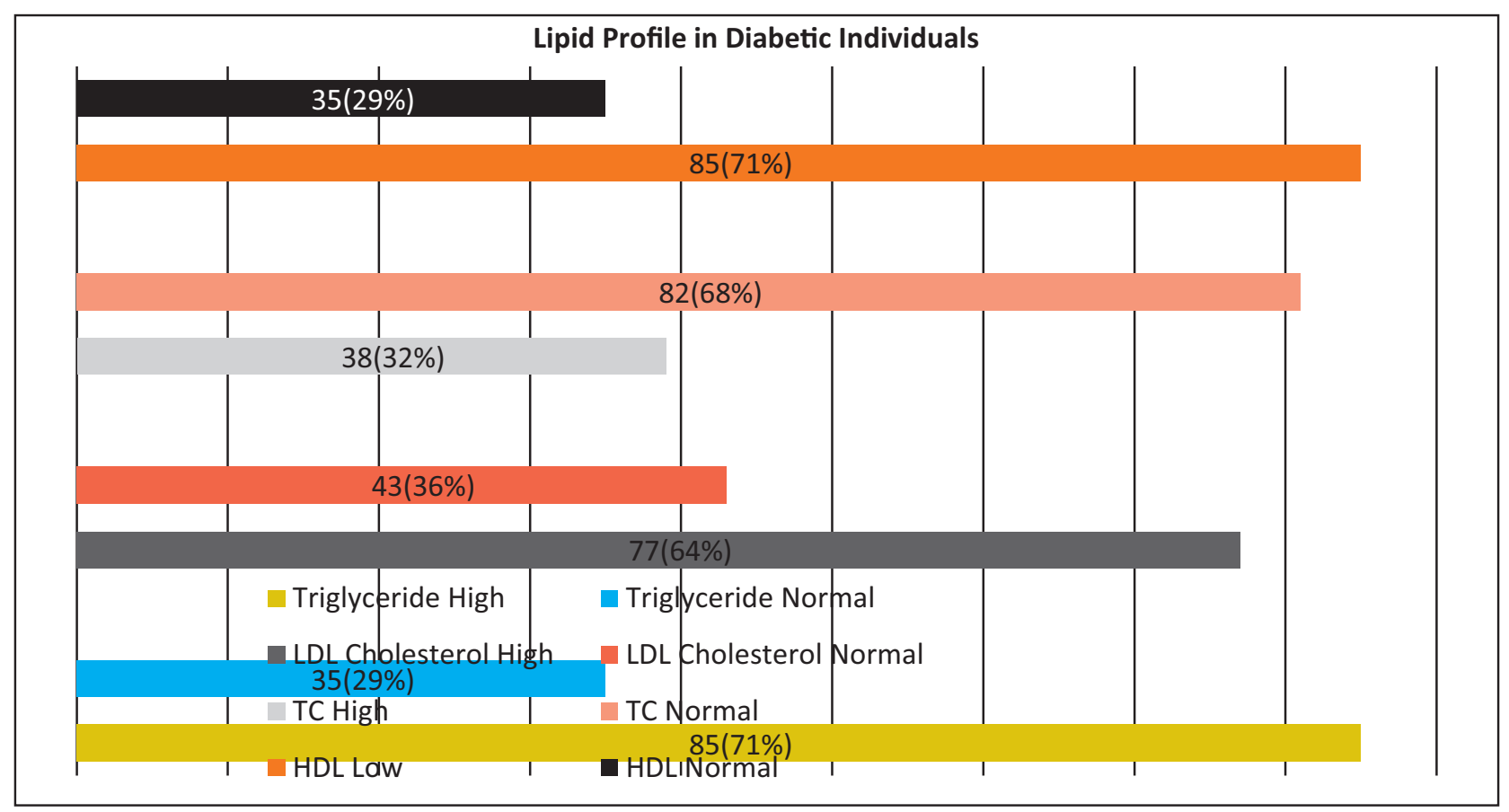

Figure 1: Pattern of Dyslipidemia in patients with Diabetes Mellitus

\section{DISCUSSION}

Dyslipidemia is a modifiable risk factor which should be identified and treated to decrease the mortality and morbidity from cardiovascular and cerebrovascular diseases.

In this study, 71\% patients have high TG, 71\% have low HDL, 64\% have high LDL and 32\% have high TC. Similar findings were seen in study done by Ullasini et al. ${ }^{15}$ which showed $78 \%$ have high TG and $85 \%$ have low HDL. Another study conducted by Sehran et al. ${ }^{16}$ showed more than $50 \%$ of diabetes patients have raised TG, $54 \%$ have elevated LDL and 73\% have decreased HDL. In this study, there were more females than male participants. This study showed that the mean TG was higher in male than female. However, the mean HDL was lower in male than female. This trend of dyslipidemia can be due to consumption of food rich in carbohydrates, fat and lack of physical activity.

Although diabetes and obesity commonly coexist, mean BMI in this study was 25.9, which falls in overweight range. As the patients included in this study were diabetic for long time, this BMI finding can be assumed due to improvement in diet and physical activity over a long period of time.

Our study revealed high TG, low HDL, and high LDL in patient with Diabetes Mellitus type-2. Monitoring the lipid profile in regular basis might play a role to detect and treat the lipid abnormalities in patient with diabetes mellitus. Dyslipidemia management in patient with type IIDM should be started with life style changes, comprising of increased physical activity, dietary modifications and weight control strategies. Tight glycemic control with use of antidiabetic agents and insulin is shown to be beneficial in correcting dyslipidemia ${ }^{17,18}$.

As the study was carried out among patients attending OPD only, results can't be generalized to general population. Also factors like pattern of glycemic control, duration of disease were not considered so further studies are required in this issue. 


\section{CONCLUSION}

The most common lipid abnormality in DM is high triglyceride and low HDL. But this study showed that some diabetic individuals have a lipid abnormality while others do not. This shines light on the importance of regular testing for lipid profile in diabetic individual because we cannot reasonably predict when a patient

\section{REFERENCES}

1. Shaw JE, Sicree RA, Zimmet PZ. Global estimates of the prevalence of diabetes for 2010 and 2030. Diabetes Res Clin Pract. Elsevier. 2010;87(1):4-14. [Full Text | DOI]

2. Gyawali B, Sharma R, Neupane D, Mishra SR, van Teijlingen $E$, Kallestrup P. Prevalence of type 2 diabetes in Nepal: a systematic review and meta-analysis from 2000 to 2014. Glob Health Action. 2015;8:29088. [DOI]

3. Chattanda SP, Mgonda YM. Diabetic dyslipidemia among diabetic patients attending specialized clinics in Dar es Salaam. Tanzania Medical Journal. 2008;23(1):08-11. [Full Text | DOI]

4. Taskinen M.R. Diabetic dyslipidemia. Atheroscler Suppl. 2002;3(1):47 - [PubMed] [Google Scholar]

5. Krishna P, Roopakala, Prasanna KM. Dyslipidemia in type 1 diabetes mellitus in the young. Int J Diabetes Dev Ctries. 2005;25(4):110-2. [Full Text]

6. Pant $P$, Hamal $P$, Gurung D, Upreti K, Subedi K. Lipid profile in a tertiary care center. J Nepal Med Assoc. 2010;49(178):147-50 [Full Text | DOI]

7. lacopino AM. Periodontitis and diabetes interrelationships: role of inflammation. Ann Periodontol. 2001;6(1):125-37. [Full Text | DOI]

8. Laakso M, Lehto S, Penttila I, Pyorala K. Lipids and lipoprotein predicting coronary heart disease mortality and morbidity in patients with noninsulin dependent diabetes mellitus. Circulation. 1993;88:1421-30.[Full Text| DOI]

9. Khan SR, Ayub N, Nawab S, Shamsi TS. Triglyceride profile in dyslipidemia of type 2 diabetes mellitus. J Coll Physicians Surg Pak. 2008;18(5):270-3. [Full Text]

10. Gadi R, Samaha FF. Dyslipidemia in type 2 diabetes mellitus. Curr Diabetes Rep. 2007;7(3):228-34. [Full Text] will develop dyslipidemia. Thus, regular testing of lipid profile in diabetic individuals can detect dyslipidemia early. The optimal care for a patient with diabetes mellitus should include routine monitoring of blood sugar and serum lipid profile.

\section{Conflict of interest: None}

Source(s) of support: None

11. Wexler DJ, Grant RW, Meigs JB, Nathan DM, Cagliero E. Sex disparities in treatment of cardiac risk factors in patients with type 2 diabetes. Diabetes Care. 2005;28(3):514-520 [Full Text | DOI]

12. Regmi $P$, Gyawali $P$, Shrestha $R$, Sigdel M, Mehta KD, Majhi S. Pattern of dyslipidemia in type-2 diabetic subjects in Eastern Nepal. J Nepal Assoc Med Lab Sci. 2009;10(1):11-3. [Full Text]

13. Gyawali B, Sharma R, Neupane D, Mishra SR, van Teijlingen $E$, Kallestrup P. Prevalence of type 2 diabetes in Nepal: a systematic review and meta-analysis from 2000 to 2014. Glob Health Action. 2015;8:29088. [DOI]

14. National Cholesterol Education Program (NCEP) Expert panel on detection, evaluation, and treatment of high blood cholesterol in adults (adult treatment panel III). Third report of the National Cholesterol Education Program (NCEP) expert panel on detection, evaluation, and treatment of high blood cholesterol in adults (adult treatment panel III) final report. Circulation. 2002 Dec 17;106(25):3143421. [PubMed]

15. Kolhar U et al. Study of serum lipid profile in type 2 diabetes mellitus patients and its association with diabetic nephropathy. International Journal of Advances in Medicine. 2017;Dec;4(6):1513-6. [Full Text | DOI]

16. Bhatti SM, Dhakam S, Khan MA. Trends of lipid abnormalities in Pakistani Type-2 diabetes mellitus patients: A Tertiary Care Centre Data. Pakistan Journal of Medical Sciences. 2009;25(6):883-9. [Full Text]

17. Haffner SM. Management of dyslipidemia in adults with diabetes. Diabetes Care. 1998 Jan;21(1):160-78. [Full Text | DOI]

18. Mudaliar S, Henry RR. New oral therapies for type 2 diabetes mellitus: The glitazones or insulin sensitizers. Annual review of Medicine. 2001;52:23957. [Full Text $\mid \mathrm{DOI}]$ 